\title{
Bölgesel nöral tüp defektli gebelerin sağlıklı gebelerle karşılaştırılması
}

\section{Comparison of regional neural tube defects with healthy pregnancies}

\section{Cemile DAYANGAN SAYAN*1, Nevin SAĞSÖZ'1, Zehra Sema ÖZKAN'1', Mahmut IIlkin YERAL'1', Serkan TURSUN²}

${ }^{1}$ Kırıkkale Üniversitesi Tıp Fakültesi Kadın Hastalıkları ve Doğum ABD, Kırıkkale

${ }^{2}$ Kırıkkale Üniversitesi Tıp Fakültesi Çocuk Sağlığı ve Hastalıkları ABD, Kırıkkale, TÜRKiYE

\section{Öz}

Amaç: Nöral tüp defektleri (NTD) nöral tüpün bir bölümünün kapanmasında meydana gelen kusur sonucu ortaya çıkan ve sık görülen konjenital anomalilerdir. Dünya çapında her yıl yaklaşık 300.000 bebek NTD ile doğmaktadır ve NTD konjenital anomalilerle ilişkili neonatal ölümlerin yaklaşık olarak \%29'undan sorumlu tutulmaktadır. Bu çalışmada Kırıkkale ilinde 2014-2017 yılları arasında saptanan NTD’li gebeler ile sağlıklı gebelerin demografik özellikleri ve laboratuar bulgularını karşılaştırmayı amaçladık.

Gereç ve Yöntemler: Bu retrospektif çalışmaya NTD'i tanısı almış 27 olgu ve 30 sağlıklı gebe dahil edildi. Olguların demografik verileri ve laboratuvar değerleri kayıtlardan tarandı ve kaydedildi. Bulgular NTD'li ve sağlıklı gebelik grupları arasında karşılaştırıldı.

Bulgular: NTD'li hastaların 15 tanesi meningomyelosel, 4 tanesi anensefali, 2 tanesi ensefalosel, 2 tanesi eksensefali, 2 tanesi anensefali+ensefalosel, 1 tanesi meningomyelosel+ensefalosel ve 1 tanesi de myeloşizis tanılı idi. NTD grubunun ortalama vücut kitle indeksi kontrol grubuna göre anlamlı olarak yüksekti. Gruplar arasında laboratuvar parametreleri açısından istatistiksel olarak anlamlı bir fark yoktu.

Sonuç: Kırıkkale ilinde NTD’li ve sağlıklı gebeleri karşılaştırdığımız çalışmamızda NTD grubunda VKi'nin kontrol grubuna göre anlamlı daha yüksek olduğunu tespit ettik. Çok merkezli ve artmış popülasyonla yapılacak yeni çalışmalar, Türk toplumunda NTD risklerini ayrıntılı olarak belirlemek açısından faydalı olacaktır.

Anahtar Kelimeler: Nöral tüp defekti, gebelik, konjenital anomali

Sorumlu Yazar*: Cemile Dayangan Sayan, Kırıkkale Üniversitesi Tıp Fakültesi Kadın Hastalıkları ve Doğum ABD, Kırıkkale, TÜRKIYE Tel: +905056755247 


\section{ABSTRACT}

Aim: Neural tube defects (NTD) are congenital anomalies that occur as a result of a defect in the closure of a part of the neural tube. Worldwide, approximately 300,000 babies are born with NTD each year, and NTD is responsible for approximately $29 \%$ of neonatal deaths associated with congenital anomalies. In this study, we aimed to compare the demographic characteristics and laboratory findings of healthy pregnants with those of NTD in Kırıkkale province between 2014-2017.

Material and Methods: This retrospective study included 27 cases with NTD diagnosis and 30 healthy pregnant women. The demographic data and laboratory values of the cases were recorded from the computer records. Findings were compared between NTD and healthy pregnancy groups.

Results: Of the NTD patients, 15 were meningomyelocele, 4 were anencephaly, 2 were encephalocele, 2 were exencephaly, 2 were anencephaly + encephalocele, 1 was meningomyelocele + encephalocele and 1 was myeloschisis. The mean body mass index of the NTD group was significantly higher than the control group. There was no statistically significant difference between groups in terms of laboratory parameters.

Conclusion: In our study comparing NTD and healthy pregnancies in Kırıkkale province, we found that NTD group had significantly higher body mass index than control group. New studies with multi-centered and increased populations will be useful in detailing NTD risks in Turkish society.

Keywords: Neural tube defect, pregnancy, congenital anomaly

\section{Giriş}

Nöral tüp defektleri (NTD) nöral tüpün bir bölümünün kapanmasında meydana gelen kusur sonucu ortaya çıkan ve sık görülen konjenital anomalilerdir [1]. Söz konusu olan bu kapanma defekti genellikle fertilizasyondan sonraki üç ve dördüncü haftalarda yani kişinin henüz gebe olduğunu bilmediği dönemde gerçekleşir. Defekt nöral tübün vertebra, spinal kord, kranium ve/veya beyin gibi herhangi bir kısmını içerebilir [2]. Defekt izole bir malformasyon olarak karşımıza çıkabileceği gibi diğer malformasyonlarla kombine olarak ya da genetik bir sendromun bir parçası olarak da görülebilir [3]. NTD kardiyak malformasyonlardan sonra ikinci en sık görülen konjenital anomalilerdir. Prevelansı coğrafik bölgelere ve çevresel faktörlere göre değişiklik gösterir [4]. Dünya çapında her yıl yaklaşık 300.000 bebek NTD ile doğmaktadır ve NTD konjenital anomalilerle ilişkili neonatal ölümlerin yaklaşık olarak \%29'undan sorumlu tutulmaktadır [5]. 2016'da yapılan bir derlemeye göre NTD prevelansı Doğu Akdeniz'de 10.000 doğumda 21,9 iken, Avrupa'da 10.000 doğumda 9,0 ve Amerika'da ise 10.000 doğumda 5,3 olarak bildirilmiştir [4].

Sendromik olmayan NTD'nin etiyolojisi multifaktöriyel düşünülmekte olup; genetik ve çevresel faktörlerin ortak etkileri sonucu geliştikleri kabul edilmektedir . Aile hikayesi, kromozomal anormallik ya da tek gen hastalığı gibi genetik kusurlar, etnik ve coğrafi faktörler, maternal medikal hastalıklar, çeşitli medikasyonlar ve çevresel faktörler NTD ile ilişkilendirilmiştir [2]. NTD'li gebelik hikayesi, maternal ya da paternal NTD varlığı, folik asit eksikliği, pregestasyonel diyabet, maternal hipertermi, valproik asit gibi yüksek riskli antiepileptik kullanımı, radyasyon maruziyeti ve sigara NTD için belirtilen risk faktörlerinin önemli olanlarıdır [6]. Ayrıca düşük sosyoekonomik düzeye sahip toplumlarda NTD sıklığının arttığı bildirilmiştir [7]. NTD'li fetusa sahip olan bir gebeliğin antenatal takibi, yenidoğan bakımı ve etkilenmiş çocuğun uzun dönem bakımı önem arz eder. Her ne kadar NTD'nin ağır formları intrauterin dönemde veya doğumdan hemen sonra ölümle sonuçlansa da yaşamla bağdaşabilen meningomyelosel gibi olgulara yeterli bakım verildiği taktirde bunların $\% 75^{\prime}$ inin erken gençlik yaşlarına ulaşabildiği bilinmektedir [8]. Ancak bu hastaları uzun dönemde ciddi nörolojik, ortopedik ve ürolojik sekeller beklemektedir ve yaşam boyu sağlık giderleri önemli mali yüke sebep olmaktadır [9].

Bu çalışmada Kırıkkale ilinde 2014-2017 yılları arasında saptanan NTD'li gebeler ile sağlıklı gebelerin demografik özellikleri ve laboratuar bulgularını karşılaştırmayı amaçladık.

\section{Gereç ve Yöntem}

Bu retrospektif çalışmaya 2014 ile 2017 yılları arasında Kırıkkale Üniversitesi Tıp Fakültesi Kadın Hastalıkları ve Doğum Anabilim Dalı́nda rutin antenatal takip sırasında saptanmış ya da ikinci basamak dış merkezlerden refere edilerek takibe alınmış NTD'li 27 olgu (NTD grubu) ile antenatal takipleri aynı klinikte devam etmiş ve sağlıklı bebek doğumu ile sonuçlanmış 30 sağlıklı gebe (kontrol grubu) dahil edildi. Gruplar gebelik haftaları açısından denkleştirildi. Yaş, vücut kütle indeksi (VKI), gravida, parite, eğitim düzeyi, gebelik haftası, maternal medikal hastalık varlığı, kronik ilaç kullanım öyküsü, NTD'nin lokalizasyonu ve kesin tanısı, gebelik öncesi ve gebelikte folik asit kullanımı, önceki gebelikte NTD öyküsü, maternal ya da paternal NTD öyküsü, gebeliğin ilk trimesterinde ateşli hastalık geçirme öyküsü, sigara kullanımı, hemoglobin $(\mathrm{Hb})$, beyaz küre (WBC), açlık kan şekeri (AKŞ) ve tiroid stimülan hormon (TSH) değerleri kayıtlardan tarandı ve kaydedildi. 
Veriler SPSS 16.0 (USA) programı kullanılarak bilgisayar ortamına aktarıldı ve istatistiki değerlendirme yapıldı. Sürekli değişkenler ortanca (minimum-maksimum) veya ortalama 土standart sapma olarak belirtilirken; kategorik değişkenler sayı ve yüzde olarak sunuldu. Gruplar arası verilerin karşılaştırılmasında; sürekli değişkenlerin dağılım özelliğine göre Student t test veya Mann Whitney-U testi kullanılırken, kategorik verilerde ise Ki-kare testi kullanıldı. P凶0,05 değeri istatistiki olarak anlamlı kabul edildi.

\section{Bulgular}

NTD grubu kendi içinde incelendiğinde hastaların 15 tanesi meningomyelosel, 4 tanesi anensefali, 2 tanesi ensefalosel, 2 tanesi eksensefali, 2 tanesi anensefali+ensefalosel, 1 tanesi meningomyelosel+ensefalosel ve 1 tanesi de myeloşizis tanılı idi. İki fetal meningomyelosel tanılı gebe dışında geri kalan tüm vakalara tıbbi tahliye işlemi uygulandı. Gebeliğin devamını isteyen iki olgunun birinde 37. gebelik haftasında kliniğimizde 7/9 APGAR skorlu, 3200 gram ağırlığında, canlı bir fetüs doğumu gerçekleşti (Tablo 1).

\begin{tabular}{|l|c|c|}
\hline Tablo 1. Nöral tüp defekti paternleri & & \\
& Sayı & Yüzde \% \\
\hline Meningomyelosel & 15 & 55.6 \\
\hline Anensefali & 4 & 14.8 \\
\hline Eksensefali & 2 & 7.4 \\
\hline Ensefalosel & 2 & 7.4 \\
\hline Anensefali-Ensefalosel & 2 & 7.4 \\
\hline Meningomyelosel+Ensefalosel & 1 & 3.7 \\
\hline Myeloşizis & 1 & 3.7 \\
\hline
\end{tabular}

Grupların demografik verilerinin karşılaştırılması Tablo-2' de gösterilmiştir. NTD grubunun ortalama yaşı 27,6 yıl iken kontrol grubunun ortalama yaşı 26,8 yıl idi. VKi ortalaması NTD grubu için 27,6 kg/m2 iken kontrol grubunda 23,5kg/ m2 olarak hesaplandı. NTD grubunun ortalama VKi kontrol grubuna göre anlamlı olarak yüksekti $(p=0.014)$. NTD grubundaki hastaların \% 29,6'sı ilköğretim, \% 55,6'sı lise, $\% 14,8$ 'i üniversite mezunu iken kontrol grubundaki hastaların \% 33,3'ü ilköğretim, \% 46,7'si lise, \%20'si üniversite mezunu idi. NTD grubunda hastalardan bir tanesinde daha önce NTD' li gebelik öyküsü mevcut iken iki tanesinde de gebeliğinin ilk üç ayında üriner sistem enfeksiyonuna bağlı yüksek ateş ve hastaneye yatış öyküsü mevcut idi. NTD grubunun \%14,8'inde sigara tüketimi mevcut iken kontrol grubunda bu oran \% 10 idi. Her iki grupta da konsepsiyon öncesi folik asit kullanımı bulunmamaktaydı. Konsepsiyon sonrası folik asit kullanma süresi ortalama olarak NTD grubu ve kontrol grubu için sırası ile 3,7 ve 4,1 hafta idi. Gruplar arasında yaş, gravida, parite, gebelik haftası, eğitim düzeyi, konsepsiyon sonrası folik asit kullanımı, NTD öyküsü, gebeliğin ilk üç ayında ateşli hastalık öyküsü ve sigara kullanımı açısından istatistiki açıdan anlamlı bir fark saptanmadı ( $\mathrm{p \bigotimes 0,05)}$ (Tablo 2).

\begin{tabular}{|c|c|c|c|}
\hline & $\begin{array}{l}\text { NTD grubu } \\
(\mathrm{N}: 27)\end{array}$ & $\begin{array}{c}\text { Kontrol } \\
\text { grubu (N:30) }\end{array}$ & $\begin{array}{c}\mathrm{p} \\
\text { değeri }\end{array}$ \\
\hline Yaş (yıl) & $27.6 \pm 6.6$ & $26.8 \pm 6.8$ & 0,614 \\
\hline Gravida & $2.5(1-6)$ & $2.2(1-4)$ & 0,660 \\
\hline Parite & $1.2(0-4)$ & $1(0-3)$ & 0,507 \\
\hline Kilo (kg) & $70.1 \pm 15.6$ & $68.4 \pm 11.5$ & 0,491 \\
\hline BMI (kg/boy2) & $27.6 \pm 5.1$ & $23.5 \pm 2.7$ & 0,014 \\
\hline Gebelik Haftası & $16.4 \pm 2.5$ & $16.3 \pm 2.5$ & 0,860 \\
\hline $\begin{array}{l}\text { Eğitim düzeyi } \\
\text { • İlköğretim (\%) } \\
\text { • Lise (\%) } \\
\text { • Üniversite (\%) }\end{array}$ & $\begin{array}{c}8(\% 29.6) \\
15(\% 55.6) \\
4(14.8)\end{array}$ & $\begin{array}{c}10(\% 33.3) \\
14(\% 46.7) \\
6(\% 20.0)\end{array}$ & 0,779 \\
\hline $\begin{array}{l}\text { Konsepsiyon sonrası fo- } \\
\text { lik asit kullanımı (hafta) }\end{array}$ & $3.7 \pm 2.0$ & $4.1 \pm 2.2$ & 0.783 \\
\hline NTD öyküsü varlığı (\%) & $1(\% 3.7)$ & $0(\% 0)$ & 0.474 \\
\hline Sigara kullanımı(\%) & $4(\% 14.8)$ & $3(\% 10.0)$ & 0.589 \\
\hline $\begin{array}{l}\text { Maternal hipertermi } \\
\text { öyküsü varlığı (\%) }\end{array}$ & $2(\% 7.4)$ & $0(\% 0)$ & 0.476 \\
\hline
\end{tabular}

Laboratuvar parametreleriaçısındangruplarkarşılaştırıldığında (Tablo 3), NTD grubunda ortalama Hb düzeyi 11,8 g/dL, ortalama WBC düzeyi 10,2x 103/ $\mu \mathrm{L}$, ortalama açlık kan şekeri düzeyi $92,5 \mathrm{mg} / \mathrm{dL}$ ve ortalama TSH düzeyi 1,6 $\mu \mathrm{U} / \mathrm{mL}$ iken; kontrol grubunda bu parametre düzeyleri sırası ile 11,6 g/dL, $9,9 \times 103 / \mu \mathrm{L}, 89,6 \mathrm{mg} / \mathrm{dL}$ ve 1,9 $\mu \mathrm{U} / \mathrm{mL}$ idi. Gruplar arasında laboratuvar parametreleri açısından istatistiksel olarak anlamlı bir fark yoktu (pष0.05).

\begin{tabular}{|c|c|c|c|}
\hline & $\begin{array}{l}\text { NTD grubu }(\mathrm{N}: 27) \\
\text { ortalama } \pm \mathrm{SD}\end{array}$ & $\begin{array}{c}\text { Kontrol } \\
\text { grubu (N:30) } \\
\text { ortalama } \pm S D\end{array}$ & $\begin{array}{c}\mathrm{p} \\
\text { değeri }\end{array}$ \\
\hline $\mathrm{Hb}(\mathrm{g} / \mathrm{dl})$ & $11.8 \pm 0.8$ & $11.6 \pm 0.9$ & 0.543 \\
\hline WBC $(103 / \mu \mathrm{l})$ & $10.2 \pm 2.5$ & $9.9 \pm 2.5$ & 0.695 \\
\hline AKŞ (mg/dl) & $92.5 \pm 15.3$ & $89.6 \pm 12.3$ & 0.879 \\
\hline $\mathrm{TSH}(\mu \mathrm{U} / \mathrm{ml})$ & $1.6 \pm 0.8$ & $1.9 \pm 1.0$ & 0.725 \\
\hline
\end{tabular}

\section{Tartışma}

Çalışmamızda 2014 ile 2017 yılları arasında kliniğimizde tanı konmuş ya da dış merkezden refere edilmiş 27 NTD'li gebe ile 30 sağlıklı gebe demografik veriler ve laboratuvar bulguları açısından karşılaştırıldı. Gruplar arasında demografik veriler açısından istatistiki anlamlı bir fark gözlenmedi. Sadece NTD’li olguların ortalama VKI kontrol grubuna göre anlamlı olarak 
daha yüksek idi. Gruplar arasında Hb, WBC, AKŞ, TSH değerleri açısından anlamlı fark gözlenmemiştir.

NTD genel olarak kraniyal ve spinal olmak üzere iki gruba ayrılır. Kraniyal NTD anensefali, eksensefali, ensefalosel ve inensefali olarak sınıflanırken; spinal NTD ise spina bifida, meningosel, meningomyelosel, myeloşizis, holoraşisisiz, kraniyoraşisisiz olarak sınıflandırılır [2]. Fakat daha sıklıkla NTD açık ya da kapalı defektler olarak sınıflandırılır [4]. Olguların \% 80'ini açık NTD olan meningomyelosel, meningosel, ensefalosel ve anensefali oluşturur [2]. Zaganjor ve ark. [4] yakın zamanda yaptıkları derlemede 160 adet çalışmayı incelemişler ve olguların \% 2'sinde tek başına spina bifida, $\%$ 10'unda spina bifidatanensefali, \%1'inde spina bifida+ ensefalosel ve \%81'inde ise spina bifida+ensefalosel+anens efalinin birlikte olduğunu bildirmişlerdir. Ayriyeten vakaların \% 6'sında tam tanımlamanın yapılamadığını kaydetmişlerdir. Bizim olgularımızda da literatür ile uyumlu olarak vakalarımızın tamamını açık NTD oluşturmakta ve bunların arasında da en sık meningomyelosel olguları yer almakta idi.

NTD’nde maternal yaşın etkisi araştıııldığında literatürde sınırlı sayıda çalışmaya rastlanmaktadır. Frey ve arkadaşları yaptıkları çalışmada maternal yaşın NTD riski üzerinde etkisinin oldukça zayıf olmakla birlikte ileri yaş ve çok genç yaşın NTD risk artışıyla birlikte olabileceğini bildirmişlerdir [10]. Ancak Unusan ve ark. [11] yaptıkları çalışmada folik asit takviyesinin NTD’ni önlemedeki rolünün Türk kadınlarındaki farkındalığını araştırmışlar ve bu farkındalığın en çok 26 ve 35 yaş arasında arttığını bildirmişlerdir. Bu yaş grubundaki artmış farkındalığa bağlı folik asit kullanımı NTD insidansını azaltıyor olabilir. Materna-Kiryluk ve ark. [12] yaptıkları çalışmada genç anne yaşının NTD riskinde bir miktar artışa neden olduğunu bildirmişlerdir. Yavuzcan ve ark. [13] Düzce ilindeki NTD'ni inceledikleri çalışmalarında NTD ile anne yaşı arasında bir ilişki bulmadıklarını belirtmişlerdir. Biz de çalışmamızda NTD'li grup ile kontrol grubu arasında maternal yaş açısından anlamlı bir fark gözlemedik. Maternal yaş arttığında kromozomal anomali sıklığının arttığı düşünüldüğünde, maternal yaşın ileri olduğu NTD vakalarının sendromik NTD olabileceğini düşünmekteyiz.

NTD risk faktörleri incelendiğinde maternal obezitenin NTD riskini arttırdığına dair kanıtlar mevcuttur. VKi ile NTD arasında pozitif kolerasyon bildirilmiştir [14]. Rasmussen ve ark. [15] yaptıkları derlemede, normal kilolu kadınlarla kıyaslandığında NTD riskinin obez kadınlarda 1,7 kat ve morbid obez kadınlarda ise 3,1 kat artış gösterdiğini bildirmişlerdir. Liu ve ark. [16] yaptıkları retrospektif bir çalışmada ise NTD'nin rekürrens risk faktörlerini incelemişler ve tekrarlayan NTD olgularının VKi'nin ilk kez NTD tanısı alan gruba göre anlamlı olarak yüksek olduğunu saptamışlardır. Biz de bu çalışmalara benzer olarak NTD' li grupta VKI değerlerinin kontrol grubuna göre anlamlı derecede yüksek olduğunu tespit ettik.

NTD’nin etiyolojisinde genetik faktörlerin rol oynadığına dair önemli kanıtlardan biri de NTD'li olgularda NTD açısından pozitif aile hikayesinin risk artışına yol açtığının bilinmesidir. Bir kez NTD'li doğum öyküsü olan çiftlerin ikinci çocuğunda
NTD rekürrens riski artmıştır [17]. Bir NTD'li çocuk doğurma öyküsünden sonra, NTD'li çocuk doğurma riski \%3,2 iken, iki NTD'li çocuk doğurma öyküsünden sonra bu risk \%10'a kadar çıkmaktadır [18]. Biz çalışmamızda NTD grubunun özgeçmişini incelediğimizde yalnızca bir olguda NTD'li çocuk doğurma öyküsü olduğunu tespit ettik. Soygeçmişte NTD varlığı açısından gruplar arasında anlamlı bir fark tespit etmedik.

Gebeliğin ilk trimesterinde maternal ateşli hastalık öyküsünün NTD gelişim riskini yaklaşık üç kat arttırdığı bildirilmiştir [9]. Duong ve ark. [20] sıcak küvet ve/veya sauna kullanımı sonucu birinci trimesterde hipertermiye tekrarlayan ve uzun süreli maruziyetin doğumsal defektleri özellikle de anensefali gelişim riskini 1,7 kat arttırdığını bildirmişlerdir. Biz olgularımızı maternal hipertermi açısından incelediğimizde NTD'li iki olgunun ilk trimesterde üriner sistem enfeksiyonuna bağlı yüksek ateş ve hastaneye yatış öyküsünün olduğunu tespit ettik ancak bu açıdan gruplar arasında anlamlı bir fark gözlemedik.

NTD ile folik asit eksikliğinin ilişkisini gösteren çalışmalar oldukça eskiye dayanmaktadır. 1976 yılında Smithells ve ark. [21] folik asit eksikliğinin NTD riskini arttırdığını ilk olarak bildirmişlerdir. 1991'de yapılan çok merkezli, randomize, çiftkör koruma çalışmasında NTD hikayesi olan yüksek riskli 1817 kadın konsepsiyon öncesi ve gebeliğin ilk üç ayında 4 mg folik asit, diğer vitaminler, folik asit+vitaminler ve hiçbiri şeklinde dört grup halinde replasman yapılarak doğuma kadar takip edilmişlerdir. Prekonsepsiyonel ve gebeliğin ilk 12 haftası 4mg/ gün folik asit takviyesinin \%72 ye varan oranda NTD tekrarlama riskini azalttığını bildirmişlerdir [22]. Bunun devamında yapılan bir plasebo kontrollü çalışmada prekonsepsiyonel folik asit takviyesinin ilk kez ortaya çıkan NTD riskini azalttığı bildirilmiştir [23]. Devam eden yıllarda folik asit takviyesinin NTD riskini azaltma mekanizması kesin olarak aydınlatılamamış olsa da MRC Vitamin Çalışması tüm gebelik planlayan kadınlara konsepsiyon öncesi ve gebelikte ilk üç ay 400 mikrogram/gün ve NTD açısından yüksek risk taşıyan kadınlara da $4 \mathrm{mg} / \mathrm{gün}$ folik asit takviyesinin yaygın olarak önerilmesine neden olmuştur [24]. ACOG 2017'de yayınlanan bülteninde NTD riski taşımayan kadınlara konsepsiyon öncesi bir ay ve gebeliğin ilk üç ayında 400 mikrogram/gün folik asit takviyesini önermiştir [2]. Biz çalışmamızda her iki grubumuzda da hastaların tamamının konsepsiyon öncesi folik asit kullanmamış olduğunu saptadık. Konsepsiyon sonrası folik asit kullanma süreleri de gruplarımız arasında anlamlı bir fark göstermedi. Bu durumun hastaların folik asit kullanma sürelerine dair yaptıkları bildirimlerin doğru olmamasından kaynaklandığını düşünmekteyiz. Bazı çalışmalarda maternal eğitim düzeyinin artmasının NTD riskini azalttığı bildirilmiştir. Bu durum, eğitim düzeyi arttıkça maternal beslenme özellikleri, gelir düzeyi ve çevresel faktörlerin konu üzerine etkili olmasıyla açıklanmıştır [13,25]. Ancak biz çalışmamızda gruplar arasında maternal eğitim düzeyleri açısından anlamlı bir fark gözlemedik.

Çeşitli maternal medikal hastalıkların da NTD riskinde artışa yol açabileceği bilinmektedir. Maternal pregestasyonel diyabet bunlar arasında en iyi bilinendir ve kontrolsüz pregestasyonel 
diyabetin NTD riskini arttırdığı bilinmektedir [26]. Glukoz dengesinde rol oynayan genlerdeki polimorfizmlerin NTD riskinimodifiyeettiğidüşünülmektedir[27]. Bizimçalışmamızda pregestasyonel diyabete sahip hasta bulunmamakta idi. Grupları açlık kan şekerleri açısından karşılaştırdığımızda gruplar arasında anlamlı bir fark olmadığını gözledik. Maternal tiroid disfonksiyonunun NTD riski ile ilişkisine ait yeterli veri literatürde mevcut değildir [28]. Biz çalışmamızda maternal TSH düzeylerini gruplar arasında karşılaştırdık ve anlamlı fark olmadığını tespit ettik. Ayrıca gruplar arasında maternal $\mathrm{Hb}$ ve WBC düzeyleri açısından da anlamlı bir fark gözlemedik.

Sonuç olarak; Kırıkkale ilinde NTD'li ve sağlıklı gebeleri karşılaştırdığımız çalışmamızda NTD grubunda VKi'nin kontrol grubuna göre anlamlı daha yüksek olduğunu tespit ettik. Çok merkezli ve artmış popülasyonla yapılacak yeni çalışmalar, Türk toplumunda NTD risklerini ayrıntılı olarak belirlemek açısından faydalı olacaktır.

\section{Maddi Destek ve Çıkar ilişkisi}

Çalışmayı maddi olarak destekleyen kişi/kuruluş yoktur ve yazarların herhangi bir çıkar dayalı ilişkisi yoktur.

\section{Kaynaklar}

1. Giordan E, BortolottiC, Lanzino G, BrinjikjiW.Spinal arteriovenous vascular malformations in patients with neural tube defects. AJNR Am J Neuroradiol 2017; 28: 1

2. American College of Obstetrics and Gynecology. ACOG (American College of Obstetrics and Gynecology) Practice Bulletin: Neural tube defects. Obstet Gynecol 2017; 130: 6

3. Moretti ME, Bar-Oz B, Fried S, Koren G. Maternal hyperthermia and the risk for neural tube defects in offspring: systematic review and meta-analysis. Epidemiol 2005; 16: 216-9.

4. Zaganjor I, Sekkarie A, Tsang BL et al. Describing the prevalence of neural tube defects worldwide: a systematic literature review. PLoS One 2016; 11: 11.

5. Christianson A, Howson CP, Modell B. March of Dimesglobal report on birth defects: the hidden toll of dying anddisabled children. White Plains (NY): March of Dimes Birth Defects Foundation 2006; 12.

6. Mitchell LE. Epidemiology of neural tube defects. Am J Med Genet C Semin Med Genet 2005; 135: 88-94.

7. Grewal J, Carmichael SL, Song J, Shaw GM. Neural tube defects: an analysis of neighbourhood and individual-level socio-economic characteristics. Paediatr Perinat Epidemiol 2009; 23: 116-24.

8. Bowman RM, McLone DG, Grant JA, Tomita T, Ito JA. Spina bifida outcome: a 25-year prospective. Pediatr Neurosurg 2001; 34: 114-20.

9. Yi Y, Lindemann M, Colligs A, Snowball C. Economic burden of neural tube defects and impact of prevention with folic acid: a literature review. Eur J Pediatr 2011; 170:1391-400.

10. Frey $L$, Hauser WA. Epidemiology of neural tube defects. Epilepsia 2003; 44: 4-13.

11. Unusan N. Assesment of Turkish women's knowledge concerning folic acid and prevention of birth defects. Public Health Nutrition 2004; 7:851-5.
12. Materna-Kiryluk A, Wiśniewska K, Badura-Stronka M, et al. Parental age as a risk factor for isolated congenital malformations in a Polish population. Paediatr Perinat Epidemiol 2009; 23: 29-40.

13. Yavuzcan A, Topuz S, Çağlar M, Dilbaz S, Üstün Y, Kumru S. Düzce ilinde nöral tüp defekti saptanan olguların değerlendirilmesi. JOPP Derg 2013; 5: 125-30.

14. Stothard KJ, Tennant PW, Bell R, Rankin J. Maternal overweight and obesity and the risk of congenital anomalies: a systematic review and meta-analysis. JAMA 2009; 301: 636-50.

15. Rasmussen SA, Chu SY, Kim SY, Schmid CH, Lau J. Maternal obesity and risk of neural tube defects: a meta-analysis. Am J Obstet Gynecol 2008; 198: 611-9.

16. Liu J, Li Z, Greene NDE, Li H, Ren A. The recurrence risk of neural tube defects (NTDs) in a population with high prevalence of NTDs in northern China. Oncotarget 2017; 8: 72577-83.

17. Nussbaum RL, Mclnnes RR, Willard HF. Complex inheritance of common multifactorial disorders. In: Thompson \& Thompson genetics in medicine. 8th ed. Philadelphia (PA): Elsevier; 2016; $133-53$.

18. Bonaiti-Pellie $C$, Smith $C$. Risk tables for genetic counselling in some common congenital malformations. J Med Genet 1974; 11: 374-7.

19. Dreier JW, Andersen AM, Berg-Beckhoff G. Systematic review and meta-analyses: fever in pregnancy and health impacts in the offspring. Pediatrics 2014; 133: 674-88.

20. Duong HT, Shahrukh Hashmi S, Ramadhani T, et al. Maternal use of hot tub and major structural birth defects. Birth Defects Res A Clin Mol Teratol 2011; 91: 836-41.

21. Smithells RW, Sheppard S, Schorah CJ. Vitamin deficiencies and neural tube defects. Arch Dis Child 1976; 51: 944-50.

22. MRC Vitamin Study Research Group. Prevention of neural tube defects: results of the Medical Research Council Vitamin Study. Lancet 1991; 338: 131-7.

23. 23. Czeizel $A E$, Dudas I. Prevention of the first occurrence of neural-tube defects by periconceptional vitamin supplementation. N Engl J Med 1992; 327: 1832-5.

24. 24. Wilson RD, Wilson RD, Audibert F, et al. Pre-conception folic acid and multivitamin supplementation for the primary and secondary prevention of neural tube defects and other folic acid-sensitive congenital anomalies. Genetics Committee. J Obstet Gynaecol Can 2015; 37: 534-52.

25. Zhang X, Li S, Wu S, et al. Prevalence of birth defects and risk-factor analysis from a population based survey in Inner Mongolia, China. BMC Pediatr 2012; 12: 125.

26. Wu Y, Wang F, Fu M, Wang C, Quon MJ, Yang P. Cellular stress, excessive apoptosis, and the effect of metformin in a mouse model of type 2 diabetic embryopathy. Diabetes 2015; 64: 2526-36.

27. Lupo PJ, Canfield MA, Chapa C, et al. Diabetes and obesity-related genes and the risk of neural tube defects in the national birth defects prevention study. Am J Epidemiol 2012;1 76: 1101-9.

28. Ceyhan ST, Beyan C, Atay V, et al. Serum vitamin B12 and homocysteine levels in pregnant women with neural tube defect. Gynecol Endocrinol 2010; 26: 578-81. 